\title{
Recursos manuais e não-manuais na expressão de intensidade em
}

\author{
Libras
}

\section{Manual and nonmanual resources to express intensity in Libras}

\author{
Thiago Steven dos Santos ${ }^{1}$
}

André Nogueira Xavier ${ }^{2}$

DOI: $10.28998 / 2317-9945.2019 n 63 p 120-137$

\section{Resumo}

Em seu estudo sobre intensidade em Libras, Xavier (2014) revelou que a duplicação de mãos não é obrigatória, mas apontou que mudanças nas características manuais e não-manuais dos sinais parecem ser. Este trabalho objetiva analisar essas mudanças apontadas pelo autor, por meio da análise de sete sinais, a saber, CHUVA, EXPERIÊNCLA, NÄO-SABER, ALÍVIO, VONTADE, FACIL $e$ SOFRER. Essa análise se deu por meio do software livre Elan, que permitiu registrar, de forma sincronizada aos dados em vídeo, descrições relacionadas ao comportamento dos articuladores não-manuais (sobrancelhas, olhos, bochechas, boca, cabeça e tronco) e às características dos articuladores manuais (configuração de mão, orientação da palma, localização e movimento). Os resultados revelaram que, apesar do emprego de diversos recursos manuais e não-manuais, diferentemente do que hipotetizou Xavier, nenbum deles parece ser obrigatório.

Palavras-chave: Intensidade. Recursos manuais. Recursos não-manuais

\begin{abstract}
In his study regarding intensity in Libras, Xavier (2014) revealed that hand doubling is not obligatory. However, the author suggested that changes in the manual and non-manual characteristics of the signs appear to be. This work aims to analyze these changes pointed out by Xavier, through the analysis of seven signs, namely, RAIN, EXPERIENCE, NOT-KNOW, RELIEF, WILL, EASY and SUFFER. The analysis was performed using the free software Elan, which allowed descriptions, synchronized with the video data, of the behavior of non-manual articulators (eyebrows, eyes, cheeks, mouth, head and torso) and characteristics of the manual articulators (band configuration, palm orientation, location and movement). The results have revealed that despite the use of various manual and nonmanual resources, unlike Xavier hypothesized, none of them seems to be obligatory.
\end{abstract}

Keywords: Intensity. Manual resources. Nonmanual resources

Recebido em: 24/12/2018.

Aceito em: 11/05/2019.

\footnotetext{
${ }^{1}$ Licenciado em Letras Libras pela Universidade Federal do Paraná.

${ }^{2}$ Doutor em Linguística pela Universidade Estadual de Campinas. Professor do curso de Letras Libras da Universidade Federal do Paraná.
} 


\section{Introdução}

Ao analisar a intensificação na língua inglesa, Benzinger (1971) evidencia que ela é expressa por diferentes recursos linguísticos ${ }^{3}$. Dentre os recursos identificados por ela, está o uso de hipérboles ou expressões de exagero, por exemplo: by all means (de todos os modos), utilizado para exagerar e intensificar frases afirmativas, ou not at all (de jeito nenhum), empregado em frases negativas; o uso de palavras inerentemente intensas, por exemplo: gigantic (gigante), famished (faminto), que expressam maior intensidade em comparação, respectivamente, com as palavras big (grande) e bungry (faminto); palavras profanas, tais como hell (inferno) e damn (droga, maldição); exclamações (ah!, ob!, ouch!, hooray!, yippee!); formas sonoramente simbólicas (slam sugere maior intensidade do que close forcefully (fechar com força)); simples repetição: "He is a big, big man" (Ele é um grande, grande homem) ou "Hurry, hurry" (Apresse-se, apresse-se); uso de vários sinônimos, por exemplo: "Clorox sanitizes and disinfects" (Clorox limpa e desinfeta), "The rooms are large and spacious" (As salas são largas e espaçosas); acento, por exemplo: He listened SO intently (Ele ouviu TÃO atentamente). Benzinger também cita preposições e partículas adverbiais que são utilizadas como recursos para intensificar no inglês, por exemplo, revert back (voltar para trás), repeat again (repetir de novo), bem como modificadores de adjetivos e advérbios, como absolutely (absolutamente), awfully (horrivelmente) etc.

Wilbur, Malaia e Shay (2012) investigaram o mesmo fenômeno na língua de sinais americana (ASL) ${ }^{4}$. Segundo as autoras, a intensificação de adjetivos em ASL consiste na realização de mudanças na sua forma de maneira que eles fiquem visualmente distintos de sua forma basal. Fuks (2016) analisou a manifestação desse processo na língua de sinais israelense (ISL) ${ }^{5}$. A autora identificou diversas estratégias para expressar intensidade nessa língua e evidencia que elas podem ser empregadas na intensificação de um mesmo sinal. Estudos sobre a intensificação nas línguas de sinais são escassos. Sendo assim, necessita-se de mais pesquisas nessa área para que uma maior compreensão das estratégias e recursos utilizados para expressar intensidade sejam identificados. Diante disso, este trabalho tem como objetivo avançar nos estudos de expressão de intensidade na Libras, dando continuidade aos estudos já realizados por Xavier $(2014,2017)$ e Santos e Xavier (2017).

Para isso, o presente trabalho foi estruturado da seguinte maneira: na primeira seção, serão apresentados os trabalhos que analisaram o fenômeno de intensidade nas línguas de sinais. Em seguida, serão descritos os procedimentos utilizados na análise dos dados investigados. Posteriormente, serão apresentados resultados e a análise.

\section{Revisão de literatura}

Wilbur, Malaia e Shay (2012), comparando a forma basal de alguns adjetivos da ASL com a sua forma intensificada, identificaram algumas mudanças: aumento na tensão da face e das mãos, acréscimo ou aumento na trajetória do movimento, soltura retardada ${ }^{6}$, franzimento da face e inclinação da cabeça. Segundo as autoras, algumas dessas mudanças

\footnotetext{
${ }^{3}$ Benzinger inclui o conceito de ênfase na definição de intensidade. No entanto, como o presente trabalho tem como foco analisar apenas a intensificação, serão citados aqui os recursos que, mais claramente, são utilizados para expressar tal processo.

${ }^{4}$ Do inglês American Sign Language.

${ }^{5}$ Do inglês Israeli Sign Language.

${ }^{6}$ Suspensão da(s) mão(s) mais alongada do que a habitual antes do início do movimento do sinal.
} 
podem ser observadas no sinal de LONGE da ASL. Comparando-se a sua forma basal (Figura 1) com a forma intensificada (Figura 2), podem-se observar mudanças nas expressões não-manuais, tais como: inclinação da cabeça e franzimento da face durante toda a produção do sinal. Também se nota uma modificação manual: o início do movimento do sinal é retardado (Figura 2a-b), dado que a mão permanece em suspensão, antes do início do movimento do sinal, por um tempo maior em relação à forma não intensificada.

Figura 1 - Sinal de LONGE na ASL em sua forma basal.
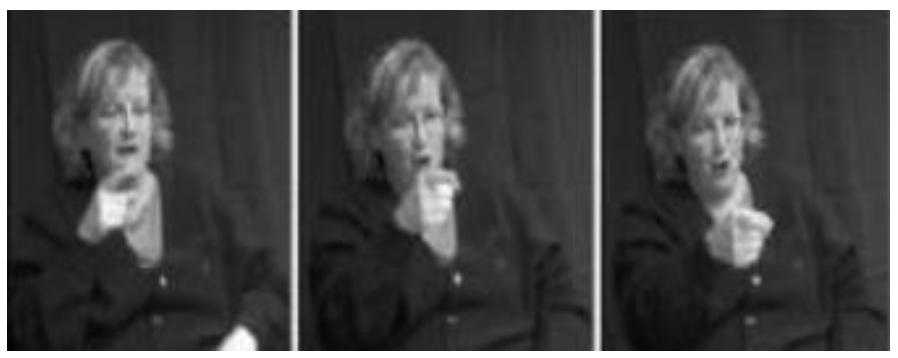

Fonte: Wilbur; Malaia; Shay (2012, p. 94).

Figura 2 - Sinal de LONGE (far) com inclinação da cabeça (a-e) e soltura retardada (a-b).

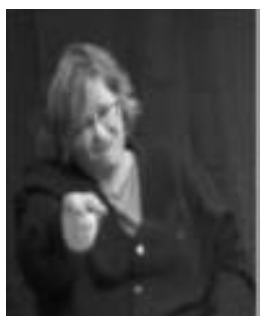

(a)

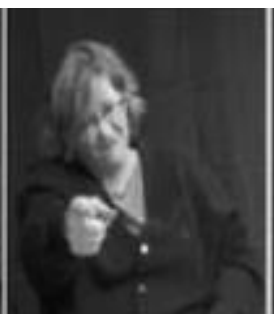

(b)

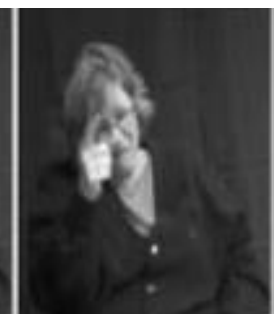

(c)

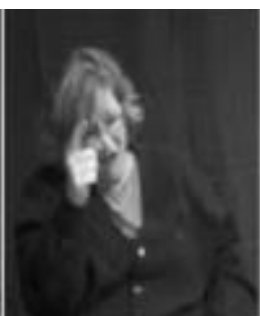

(d)

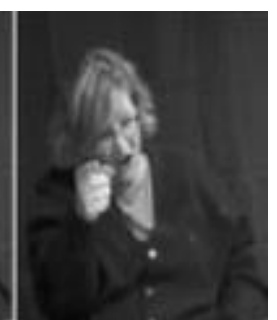

(e)

Fonte: Wilbur, Malaia e Shay (2012, p. 95).

Mais recentemente, Fuks (2016) analisa o mesmo fenômeno na língua de sinais israelense (ISL). A autora examinou a expressão de intensidade com base na análise, em contexto, de dados realizados por nove sinalizantes surdos, filhos de pais surdos e, que, portanto, têm a ISL como primeira língua. No referido estudo, os surdos sinalizaram a partir de um texto escrito em hebraico, no qual apareciam os adjetivos "ocupado", "chato", "magro", "lotado", "mimado", "bravo", "esperto", "frio", "difícil", "calmo" e "triste", acompanhados pelos advérbios "muito" e "tão".

Em suas análises, Fuks observou que os sinalizantes utilizaram três principais advérbios intensificadores da ISL: MUITO (Figura 3a), REALMENTE/VERDADE (Figura 3b) e COMPLETAMENTE (Figura 3c). MUITO foi usado em 70\% dos 56 casos de intensificação. REALMENTE/VERDADE ocorreu em 25\% do total dos recursos utilizados para intensificar. Curiosamente, esse advérbio foi acompanhado pela articulação da sílaba "fah"

\footnotetext{
${ }^{7}$ Segundo Sandler (2009), há sinais que, além de atividades manuais, envolvem o que a autora designa como lexical mouth component (componente bucal lexical). Ela afirma que determinados sinais, como parece ser o caso de REALMENTE/VERDADE, requerem formas ou movimentos particulares da boca. A autora também reporta um sinal significando THE-REAL-THING (na realidade), provavelmente o mesmo sinal reportado
} 
utilizados para intensificar.

Figura 3 - Três principais recursos utilizados para intensificar em ISL: Sinais MUITO (a), REALMENTE com a oralização da silaba "fah" (b) e COMPLETAMENTE (c).

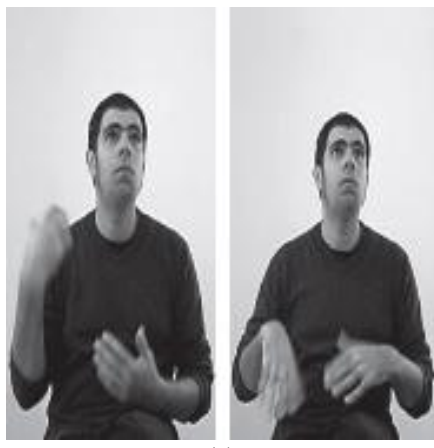

(a)

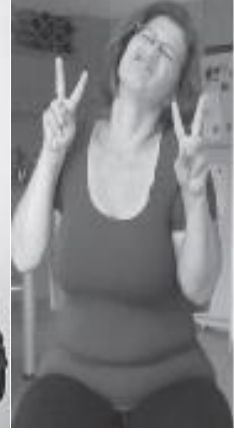

(b)

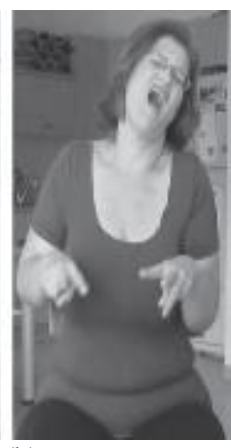

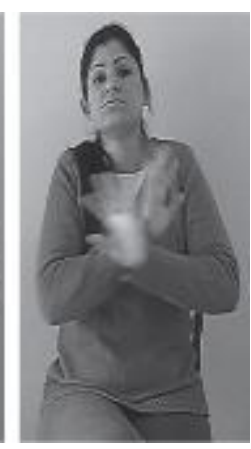

(c)

Fonte: Fuks (2016, p. 202).

Ao analisar a forma intensificada de adjetivos da ISL, a autora identificou 11 maneiras diferentes de expressar intensidade. Além disso, como sugere o quadro 1 a seguir, Fuks também observou que um mesmo sinal pode expressar intensidade por meio de mais de uma desses recursos.

Quadro 1 - Modificações manuais para expressar intensidade em adjetivos da ISL.

\begin{tabular}{|c|l|l|l|l|l|l|l|l|l|l|l|}
\hline Sinais & 1 & 2 & 3 & 4 & 5 & 6 & 7 & 8 & 9 & 10 & 11 \\
\hline OCUPAD@ & & & & & & & & & & & \\
\hline CHAT@ & & & & & & & & & & & \\
\hline MAGR@ & & & & & & & & & & & \\
\hline CHEI@ & & & & & & & & & & & \\
\hline BARULHENT@ & & & & & & & & & & \\
\hline MIMAD@ & & & & & & & & & & & \\
\hline BRAV@ & & & & & & & & & & \\
\hline ESPERT@ & & & & & & & & & & & \\
\hline FRI@ & & & & & & & & & & \\
\hline DIFÍCIL & & & & & & & & & & & \\
\hline QUI- & & & & & & & & & & & \\
ET@/CALM@ & & & & & & & & & & \\
\hline TRISTE & & & & & & & & & & \\
\hline
\end{tabular}

1) Acréscimo de movimento

2) Alongamento do movimento

3) Omissão do movimento

4) Substituição do movimento

5) Repetição do movimento

6) Suspensão
7) Mudança na localização

8) Mudança na orientação

9) Configuração de mão mais tensa

10) Mudança na localização com movimentos repetidos

11) Substituição da configuração de mão

por Fuks, que requer um movimento da boca, similar ao usado para pronunciar a silaba "fa". Nenhuma das autoras reporta qualquer relação entre esse componente bucal e a oralização total ou parcial de uma palavra do hebraico. 
Fonte: Adaptado de Fuks (2016, p. 213).

Entre os sinais analisados por Fuks que podem expressar intensidade através de modificações diferentes em seus parâmetros está OCUPAD@. Segundo a autora, quando intensificaram esse sinal, alguns sujeitos o produziram tal como em sua forma de citação (Figura 4), porém acrescentando advérbios (REALMENTE/VERDADE e MUITO, ver figura $3 \mathrm{a}$ e figura $3 \mathrm{~b})$.

Figura 4 - Forma de citação do sinal OCUPAD@.

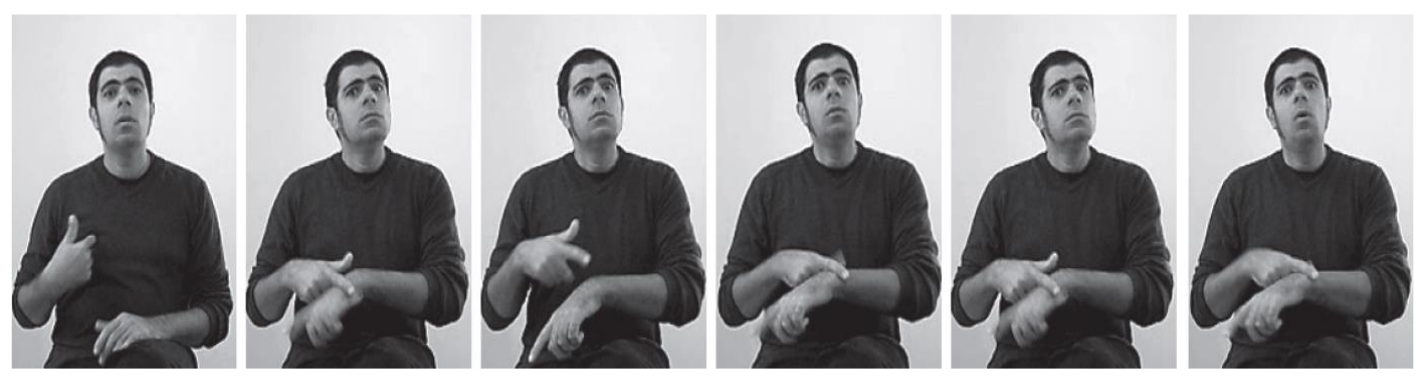

Fonte: Fuks (2016, p. 214).

Além dessa estratégia de expressão de intensidade, cinco sinalizantes modificaram a forma basal de OCUPAD@ por meio de quatro outras estratégias diferentes. Uma delas consistiu na repetição do movimento em lugares diferentes, como sugerem as figuras $4.1 \mathrm{e}$ 4.5.

Figura 4.1 - Sinalização intensificada do sinal OCUPAD@: repetição domovimento em lugares diferentes.
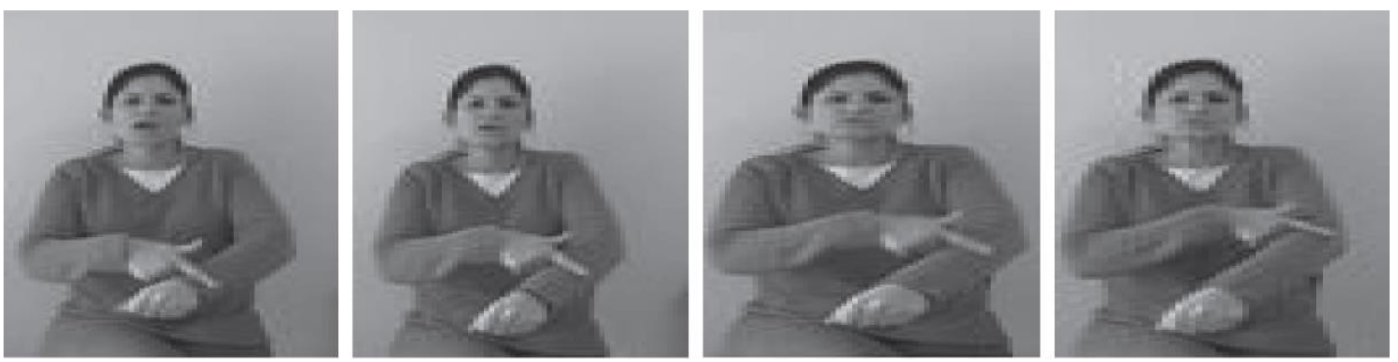

Fonte: Reproduzida de Fuks (2016, p. 24)

Outra estratégia envolveu a substituição do movimento original do sinal por um movimento com contato permanente e mais longo. Precisamente, como se pode ver na figura 4.2 a seguir, um dos sinalizantes substituiu o movimento realizado na forma de citação por um movimento que se inicia em seu punho e desliza até a extremidade superior do antebraço. 
Figura 4.2 - Sinalização intensificada do sinal OCUPAD@: substituição do movimento.

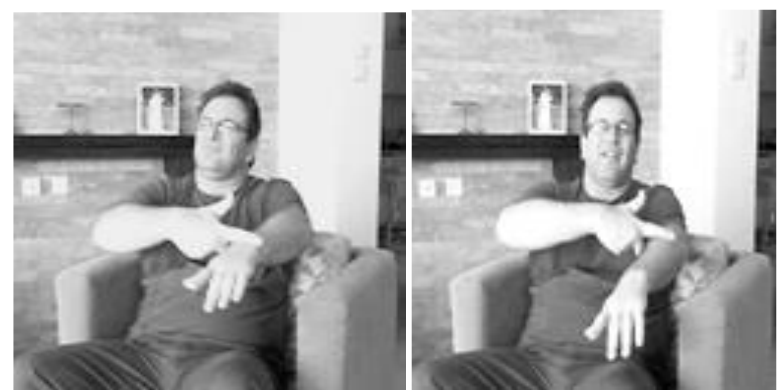

Fonte: Fuks (2016, p. 24).

A terceira estratégia de expressão de intensidade identificada por Fuks para o mesmo sinal consistiu na omissão do movimento da forma de citação. Especificamente, uma das sinalizantes, ao produzir a forma intensificada de OCUPAD@, omitiu o movimento através do qual a mão dominante toca o punho da mão não-dominante, iniciando o sinal com um movimento reto que toca a região cubital do antebraço nãodominante (Figura 4.3).

Figura 4.3 - Sinalização intensificada do sinal OCUPAD@: omissão do movimento.

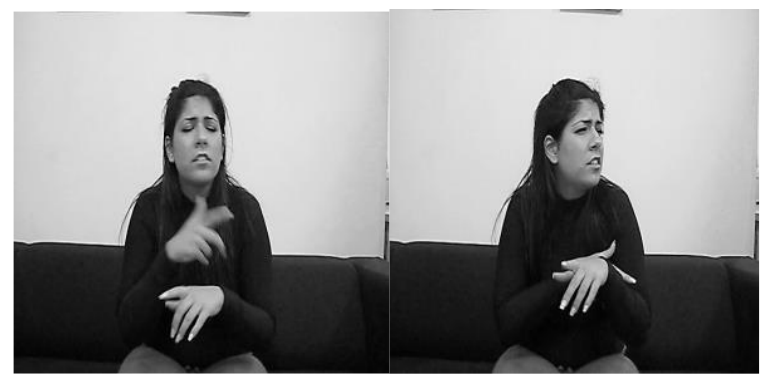

Fonte: Fuks (2016, p. 25).

Por fim, Fuks também identificou um caso de expressão de intensidade no sinal OCUPAD@ que envolveu a substituição do movimento canônico do sinal por um movimento reto (Figura 4.4). Em outras palavras, desta vez, um dos sinalizantes realizou um movimento reto repetidamente na localização que corresponde à inicial na forma de citação. A sinalizante repetiu o movimento três vezes enquanto, simultaneamente, também oralizava em hebraico a palavra "ocupado" (Figura 4.4).

Figura 4.4 - Sinalização intensificada do sinal OCUPAD@: substituição do movimento.
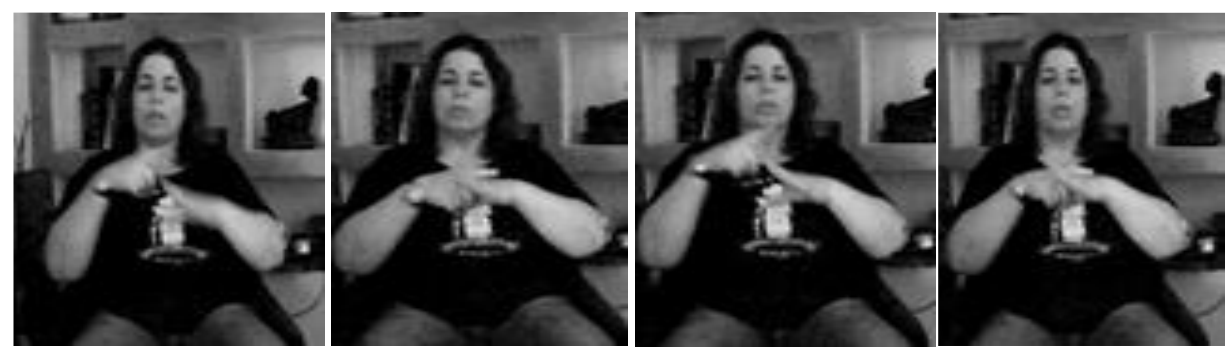

Fonte: Fuks (2016, p. 25). 
Fuks documenta que o mesmo sinalizante que intensificou o sinal OCUPAD@por meio da posposição (Figura 4) de um advérbio empregou, em um segundo momento, uma modificação na forma do sinal, ao produzi-lo nesse mesmo contexto. Precisamente, nessa segunda produção, ele repete o movimento em lugares diferentes enquanto, simultaneamente, infla as bochechas e na sequência utiliza o advérbio MUITO, como indica a figura 4.5.

Figura 4.5 - Sinal EU (1); Sinal OCUPAD@ intensificado: repetição do movimento em lugares diferentes (26). Sinal MUITO (7-8).

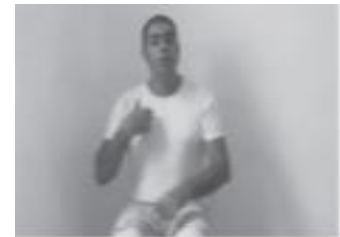

1

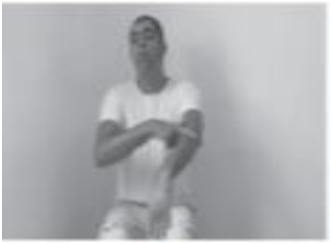

5

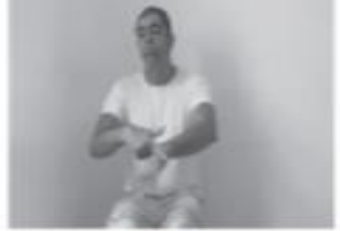

2

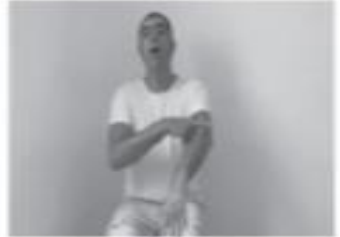

6

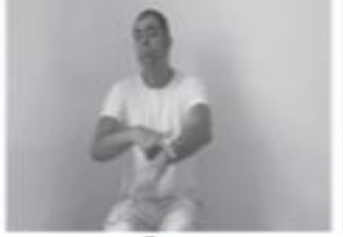

3

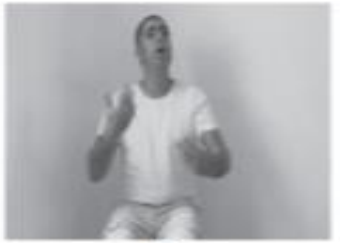

7

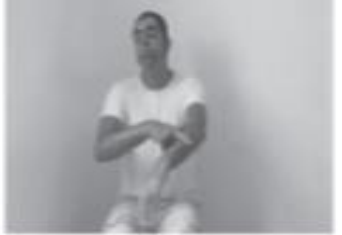

4

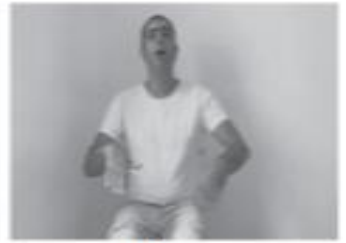

8

Fonte: Fuks (2016, p. 26).

Fuks afirma que o alongamento do movimento é uma das estratégias mais empregadas na ISL para expressar intensidade. Como exemplo, ela apresenta a produção do sinal MIMAD@(Figuras 5.2 e 5.4).

Figura 5 - A forma de citação de MIMAD@ (5.1-5.2) e a forma contextual: muito MIMAD@ (5.35.4).

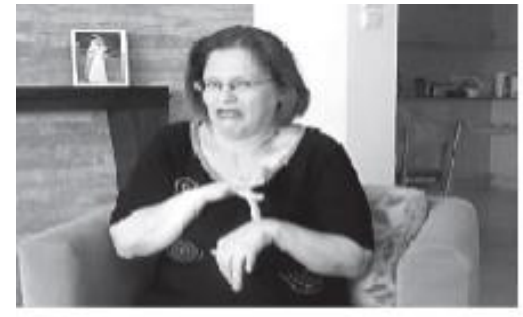

1

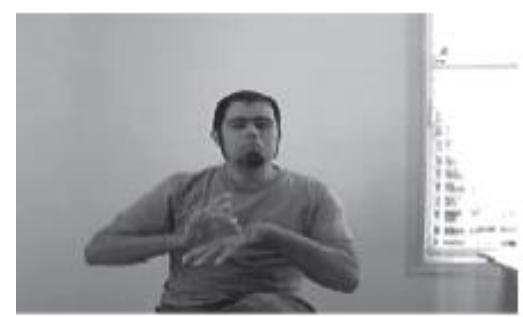

3

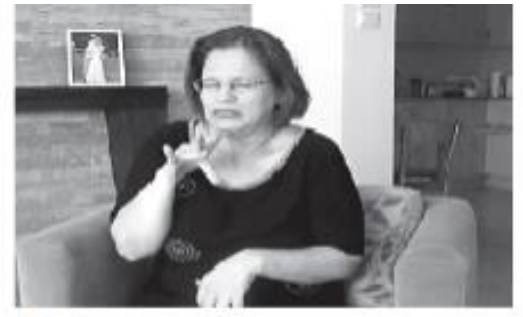

2

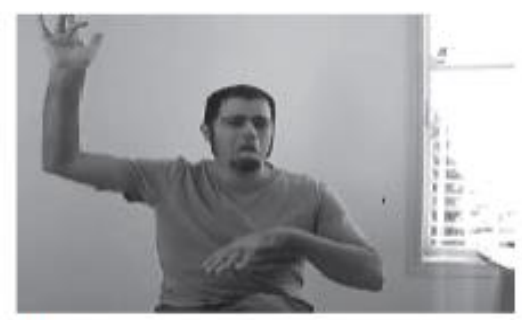

4

Fonte: Fuks (2016, p. 15).

Uma outra estratégia para expressar intensidade utilizada por alguns sinalizantes foi 
o alongamento da suspensão inicial ${ }^{8}$. Essa estratégia consiste em manter a mão alguns segundos a mais na localização inicial do sinal. A autora identificou casos em que, simultaneamente ao alongamento da suspensão inicial, alguns sinalizantes também fizeram um movimento lateral com a cabeça ou apresentaram uma expressão mais tensa. Fuks apresenta uma produção interessante do sinal CHEI@, na qual um sinalizante utiliza o alongamento da suspensão inicial como estratégia para intensificar (Figura 6.1-6.2). Entretanto, a autora menciona que, ao solicitar que o mesmo sujeito produzisse o mesmo sinal uma outra vez, ele utilizou uma estratégia diferente: a repetição de movimentos (Figura 6.3-6.5).

Figura 6 - Intensificando o sinal de CHEI@ utilizando duas estratégias: alongamento da suspensão inicial (6.1-6.2); repetição do movimento (6.3-6.5).

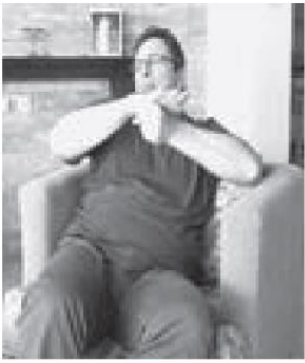

1

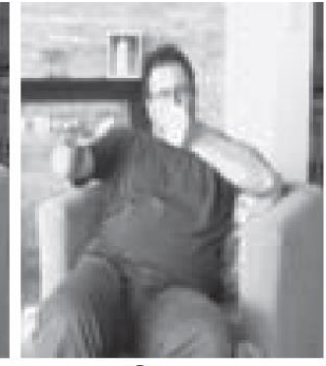

2

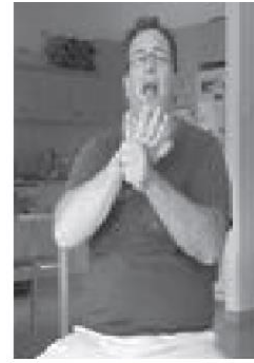

3

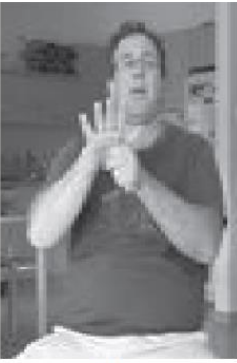

4

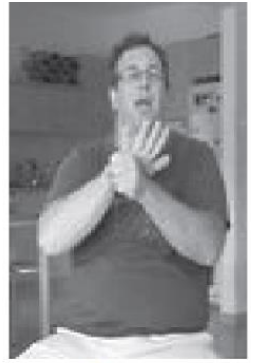

5

Fonte: Fuks (2016, p. 20).

Essas observações levaram Fuks a tratar a expressão de intensidade na ISL de forma diferente daquela que se pode presumir do trabalho de Wilbur, Malaia e Shay (2012) a respeito do mesmo processo na ASL. Para a autora, a expressão de intensidade na ISL não é um processo gramatical, mas sim gestual, dada a grande variabilidade tanto intra quanto intersujeito.

Em relação à Libras, o primeiro estudo sobre intensidade, realizado por Xavier (2014), focou na duplicação de mãos. O autor analisou 32 sinais produzidos por 12 sujeitos surdos (seis do sexo masculino e seis do sexo feminino), nascidos e residentes na cidade de São Paulo. De acordo com os resultados, $50 \%$ dos sujeitos que participaram do estudo duplicaram o número de mãos pelo menos uma vez quando produziram a forma intensificada de pelo menos um dos 32 sinais analisados. Os outros 50\% nunca o fizeram. Sendo assim, Xavier concluiu que a duplicação de mãos para expressar intensidade não é obrigatória. Apesar disso, o autor observou que todos os sujeitos, ao realizarem a forma intensificada dos sinais, produziram mudanças em alguns parâmetros articulatórios (manuais e não-manuais).

Mais recentemente, Xavier (2017) avança na descrição do processo de intensificação na Libras por meio da reanálise de dados de dois de 12 sujeitos que participaram do experimento reportado por Xavier (2014). Mais precisamente, os dados analisados pelo autor foram constituídos por três produções de 32 sinais, em sua forma isolada, em duas condições: basal e intensificada. A análise de tais produções foi realizada através do programa Elan, com o qual foram anotadas modificações nos parâmetros articulatórios, manuais (configuração de mão, orientação da palma, localização, movimento e o número de

${ }^{8}$ Com base em Wilbur, Malaia e Shay (2012), este processo é designado por Xavier (2017) e por Santos e Xavier (2017) como soltura retardada. Neste trabalho, trataremos esses casos como alongamento de suspensão, seguindo terminologia de Kita, van Gijn e van der Hulst (1998). 
mãos) e não-manuais (sobrancelhas, olhos, bochechas, boca, cabeça e tronco).

Os resultados apresentados pelo autor mostraram uma grande variedade de recursos utilizados para expressar intensidade em Libras. Precisamente, o autor identificou na forma intensificada dos sinais analisados o uso de sobrancelhas franzidas, bochechas infladas, tronco inclinado, mudanças na localização, na configuração de mão, na localização, no movimento, na orientação, no número de mãos e, na duração do sinal.

Subsequentemente, Santos e Xavier (2017) analisaram três produções dos sinais CHUVA e EXPERIÊNCIA em duas condições, basal e intensificada, realizadas por 12 sujeitos. Os autores selecionaram alguns dos aspectos manuais e não-manuais analisados por Xavier (2017). Dentre os não-manuais, examinaram os comportamentos da sobrancelha, olhos e bochechas. Já entre os manuais, analisaram a localização, a repetição e o aumento da trajetória do movimento.

A análise da forma intensificada dos sinais CHUVA e EXPERIÊNCIA revelou o emprego de sobrancelhas franzidas, de olhos semicerrados, de bochechas infladas, de expansão da localização e, consequentemente, de aumento da trajetória em sua produção. Com relação à duração dos sinais analisados, os autores observaram que a forma intensificada durou mais do que a forma basal. Essa diferença resultou estatisticamente significativa. Porém, ao testar especificamente a repetição do movimento, uma das possíveis explicações para o aumento da duração dos sinais intensificados, Santos e Xavier concluíram que, apesar de em alguns casos haver aumento no número de repetições do movimento na forma intensificada, esse recurso não resultou estatisticamente significativo.

Este estudo tem como objetivo dar prosseguimento à descrição da expressão de intensidade em Libras iniciadas por Xavier (2014, 2017) e Santos e Xavier (2017). Para isso, será apresentada uma reanálise dos sinais CHUVA e EXPERIÊNCIA e, a análise dos sinais NÃO-SABER, FÁCIL, SOFRER, VONTADE e ALÍVIO, produzidos pelos 12 sujeitos que participaram do estudo de Xavier (2014). Essa (re)análise tem como finalidade avançar na identificação das modificações realizadas nos parâmetros articulatórios (manuais e nãomanuais) para expressar intensidade.

\section{Metodologia}

As análises realizadas neste trabalho, diferentemente de Santos e Xavier (2017), que se basearam em três produções isoladas de dois sinais, CHUVA e EXPERIÊNCIA, focalizaram apenas na segunda dessas três produções, bem como na segunda produção de cinco outros sinais, a saber, NÃO-SABER, ALÍVIO, VONTADE, FÁCIL e SOFRER, tanto em sua forma basal, quanto na intensificada, produzidas por 12 sujeitos $(1 \times 2 \times 7 \times$ $12=168)$, originalmente coletados por Xavier $(2014)^{9}$. A escolha da segunda produção objetivou excluir efeitos de aprendizagem da tarefa experimental, mais comuns no início do experimento, bem como efeitos do cansaço, mais comuns em seu término. Já a seleção dos sete sinais levou em consideração a presença ou não de contato na forma de citação e, no primeiro caso, o tipo de contato: inicial, permanente ou final. Assim, foram selecionados

\footnotetext{
${ }^{9}$ Referimos o leitor à tese de doutorado de Xavier (2014) para os detalhes sobre os procedimentos metodológicos empregados por ele. É digno de nota que, no entanto, lá o autor registra que participantes assinaram termo de consentimento livre e esclarecido, o qual contou, além da versão em português, com uma versão em Libras.
} 
dois sinais sem contato com o corpo (CHUVA e EXPERIÊNCIA), dois sinais com contato inicial (NÃO-SABER e FÁCIL), dois sinais com contato permanente (ALÍVIO e VONTADE) e um sinal com contato final (SOFRER). Objetivou-se com essa seleção observar a interação entre essa característica articulatória e as estratégias de intensificação.

Originalmente, as produções de cada sinal estavam separadas por sujeito. Através do programa MovieMaker, elas foram reunidas em um arquivo de vídeo. Esse procedimento facilitou a análise da segunda produção de cada sinal. Através do software Elan, foi realizada a segmentação, isto é, a demarcação do início e do fim de cada produção. Assim como em Xavier (2017) e Santos e Xavier (2017), foram aplicados os critérios discutidos por Xavier, Tkachman e Gick (2015), ou seja, considerou-se como início do sinal o primeiro frame em que é possível perceber a mão ou o braço do sinalizante saindo do estado de repouso. Já a parte final do sinal foi delimitada através da identificação do frame em que se observa(m) a(s) mão(s) retornando para o estado de repouso (Figura 7).

Figura 7 - Print da tela do Elan com anotações.

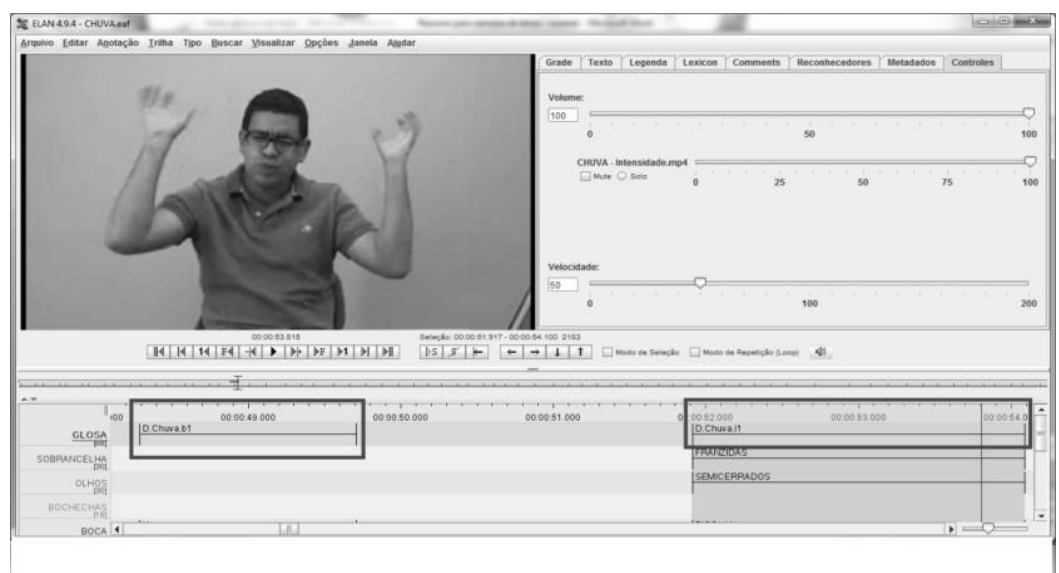

Fonte: produzida pelos autores.

Para realizar as análises, consideramos os aspectos manuais e não-manuais analisados por Xavier (2017), com exceção do número de mãos. 
Quadro 2 - Articulador(es) não-manuais e aspectos do(s) articulador(es) manual(is) anotados e analisados no Elan com acréscimo da trilha Alongamento.

\begin{tabular}{|c|c|c|}
\hline \multirow{7}{*}{$\begin{array}{l}\text { Articuladores } \\
\text { não-manuais }\end{array}$} & \multicolumn{2}{|l|}{ Glosa } \\
\hline & \multicolumn{2}{|c|}{ Sobrancelhas } \\
\hline & \multicolumn{2}{|l|}{ Olhos } \\
\hline & \multicolumn{2}{|l|}{ Bochechas } \\
\hline & \multicolumn{2}{|l|}{ Boca } \\
\hline & \multicolumn{2}{|l|}{ Cabeça } \\
\hline & \multicolumn{2}{|l|}{ Tronco } \\
\hline \multirow{6}{*}{$\begin{array}{l}\text { Aspectos do(s) } \\
\text { articulador(es) } \\
\text { manual(is) }\end{array}$} & \multicolumn{2}{|c|}{ Configuração da mão } \\
\hline & \multicolumn{2}{|c|}{ Orientação da palma } \\
\hline & \multirow[t]{2}{*}{ Localização } & Alçamento \\
\hline & & Alongamento da suspensão inicial ou final \\
\hline & \multirow[t]{2}{*}{ Movimento } & $\begin{array}{l}\text { Repetição ou aumento do número de } \\
\text { repetições }\end{array}$ \\
\hline & & Alongamento \\
\hline
\end{tabular}

Fonte: adaptado de Xavier (2017, p. 11).

Com relação à descrição dos diferentes comportamentos dos articuladores nãomanuais, anotou-se se as sobrancelhas estavam franzidas ou levantadas; se os olhos estavam arregalados ou semicerrados e se as bochechas estavam infladas ou não. Com relação à boca, as anotações levaram em conta diferentes comportamentos dos lábios, entre eles a oralização parcial ou total de palavras do português. Foram anotados também os comportamentos da cabeça e do tronco, observando-se se estavam inclinados ou em posição neutra. No caso de ocorrer inclinação, foi descrito se ela se voltava para frente, para trás, para direita ou para esquerda. As descrições referentes ao(s) aspecto(s) manual(is) registraram mudanças na configuração de mão, orientação da palma, localização (alçamento e alongamento de suspensão) e no movimento (alongamento e número de repetições). A mensuração do alongamento da suspensão se deu a partir da identificação do frame em que a mão chega à localização inicial ou final do sinal até o frame que antecede o início do movimento da fase expressiva ou de retração, respectivamente. Já a mensuração do alongamento do movimento decorreu da delimitação do próprio sinal.

Os dados foram analisados qualitativa e quantitativamente. A análise qualitativa levou em conta mudanças dos aspectos não-manuais e manuais (sobrancelha, olhos, bochechas, boca, cabeça, tronco, configuração de mão, localização e movimento) identificáveis no vídeo. A análise quantitativa, por sua vez, se deu por meio do teste estatístico Mann-Whitney $(\alpha=0,05)$, realizado no $R$, objetivando comparar a duração de suspensões ou dos sinais como um todo nas formas basal e intensificada. 


\section{Resultados}

Os dados de alguns dos sujeitos analisados, referidos neste trabalho por meio das duas primeiras letras de seus nomes, tiveram de ser excluídos. Entre as razões está o fato de que a participante CI não contrastou, de forma significativa, a produção que supostamente seria intensificada da forma basal. Outra razão envolveu a produção referente ao sinal EXPERIÊNCIA realizado por LU, que empregou um sinal, apesar de sinônimo, diferente daquele esperado por Xavier (2014). Justifica-se da mesma forma a exclusão das produções realizadas por CR1, CR2 e DA para o sinal FÁCIL. As produções de LU dos sinais CHUVA, SOFRER e VONTADE foram desconsideradas para a mensuração da duração, porque as formas basal e intensificada foram sinalizadas em sequência e sem pausa, o que impediu sua segmentação. Dessa forma, das 168 produções inicialmente consideradas, foram efetivamente analisadas 146.

Como dito anteriormente, segundo Xavier (2014), a duplicação de mãos como recurso para a expressão de intensidade na Libras não é obrigatória. Porém, o autor observou que mudanças nas expressões não-manuais e em características do movimento aparentavam ser. Apesar disso, ele não pormenorizou essas mudanças. A reanálise desses dados revelou que tanto a modificação em aspectos não-manuais quanto em características do movimento envolve diferentes subaspectos.

Das 73 produções da forma intensificada, atestamos modificações relacionadas a diferentes comportamentos de articuladores não-manuais. Dentre elas, a mais frequente, como se pode observar no gráfico da Figura 8, foi o franzimento das sobrancelhas, correspondendo a $57,5 \%$ dos casos.

Figura 8 - Comportamentos de articuladores não-manuais durante a produção da forma intensificada.

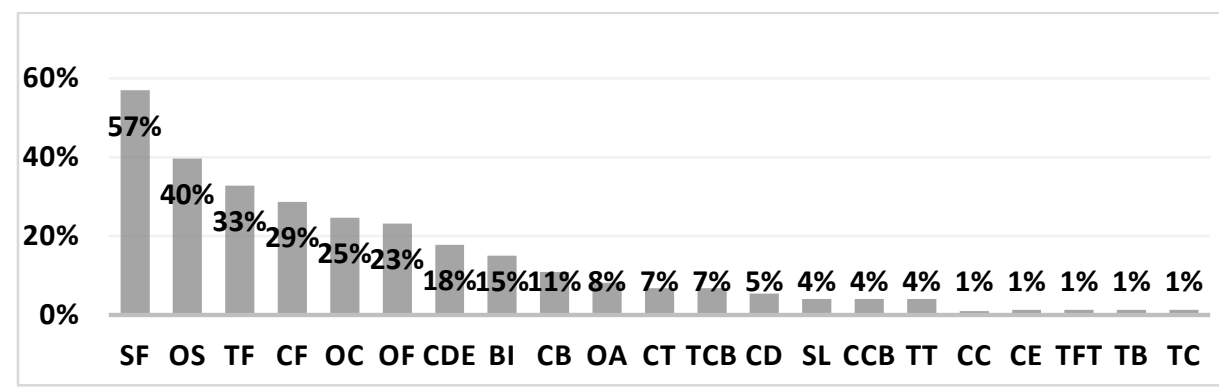

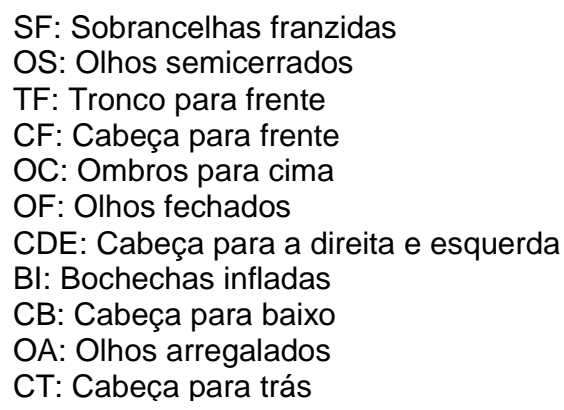

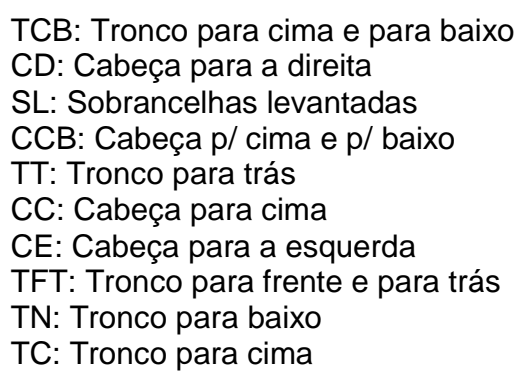

Fonte: produzida pelos autores. 
Vale ressaltar que mesmo as modificações mais frequentemente empregadas para expressar intensidade, assim como os casos de duplicação de mãos estudados por Xavier (2014), não parecem ser obrigatórias para todos os sinais.

Com relação às modificações manuais, foi analisado o alongamento da suspensão e do movimento ${ }^{10}$, bem como a repetição deste. Foram 69 ocorrências de modificações identificadas nas 73 produções de formas intensificadas. Como se pode ver no gráfico da Figura 9, a seguir, o recurso mais empregado foi o alongamento do movimento, correspondendo a 49,2\% dos recursos manuais empregados. Os casos de alongamento de suspensão inicial e final perfazem o total de 25 casos, ou seja, 36,2\%. Quanto ao aumento do número de repetições, observamos que isso ocorreu em apenas 10 produções, o que equivale a $14,4 \%$ dos dados. Assim como no caso das modificações não-manuais, as manuais também parecem não ser obrigatórias em todos os sinais para expressar intensidade.

Figura 9 - Modificações em aspectos manuais durante a produção da forma intensificada.

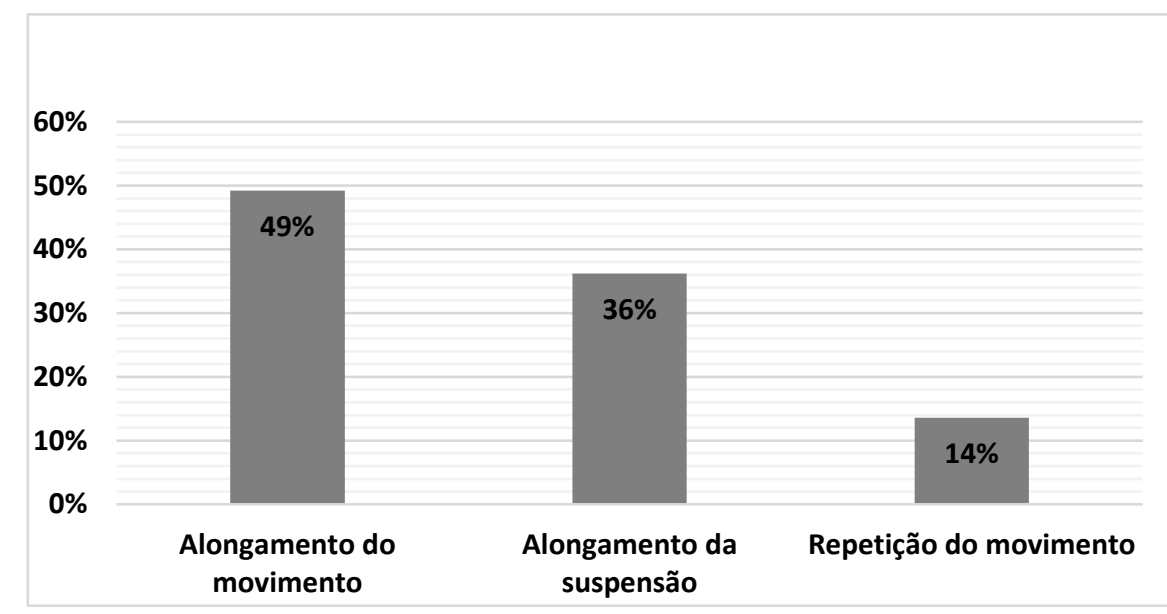

Fonte: produzida pelos autores.

Considerando-se que essas três estratégias de intensificação afetam a duração da forma intensificada, esta foi comparada à da forma basal. A diferença, indicada pelos boxplots na figura 10, foi confirmada estatisticamente pelo teste Mann-Whitney $(\alpha=0,5)(W$ $=1449$, p-valor $=7.356 \mathrm{e}-05)$.

${ }^{10} \mathrm{O}$ que designamos como alongamento do movimento neste trabalho equivale ao que designamos em trabalho anterior como "aumento da trajetória"/ "expansão da localização" (SANTOS; XAVIER, 2017). 
Figura 10 - Boxplots para duração das formas basal e intensificada dos sete sinais analisados.

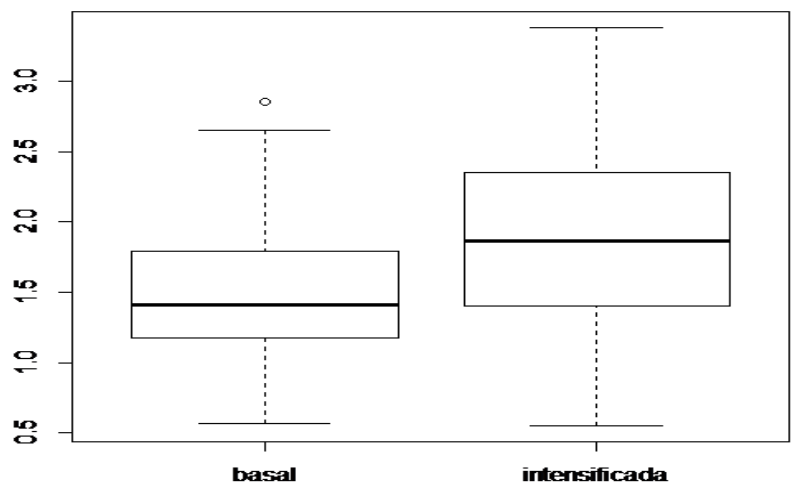

Fonte: produzida pelos autores.

\section{Análise}

Por questões de espaço, iremos apresentar de forma mais detalhada apenas as análises das sobrancelhas franzidas e do alongamento do movimento, bem como do comportamento da boca. Em relação às sobrancelhas, como se pode ver no quadro 3, a seguir, em alguns sinais o franzimento destas é mais frequente do que em outros. Precisamente, em CHUVA, NÃO-SABER e SOFRER, esse recurso foi realizado por todos ou quase todos os sujeitos na forma intensificada. Porém, nas produções dos sinais de ALÍVIO e VONTADE, ele foi utilizado por apenas um dos sujeitos.

Quadro 3 - Sobrancelhas franzidas como recurso para expressar intensidade (' $x$ ' indica que o dado foi excluído).

\begin{tabular}{|c|c|c|c|c|c|c|c|}
\hline \multicolumn{7}{|c|}{ Sobrancelhas franzidas } \\
\hline $\begin{array}{c}\text { Sujei- } \\
\text { tos } \backslash \text { Sinais }\end{array}$ & $\begin{array}{c}\text { ALÍ- } \\
\text { VIO }\end{array}$ & $\begin{array}{c}\text { CHU- } \\
\text { VA }\end{array}$ & $\begin{array}{c}\text { EXPERIÊN- } \\
\text { CIA }\end{array}$ & $\begin{array}{c}\text { FÁ- } \\
\text { CIL }\end{array}$ & $\begin{array}{c}\text { NÃO- } \\
\text { SABER }\end{array}$ & $\begin{array}{c}\text { SO- } \\
\text { FRER }\end{array}$ & $\begin{array}{c}\text { VON- } \\
\text { TADE }\end{array}$ \\
\hline CR1 & & & & X & & & \\
\hline CR2 & & & & X & & & \\
\hline DA & & & & X & & & \\
\hline ED & & & & & & & \\
\hline ER & & & & & & & \\
\hline FE & & & & & & & \\
\hline FL & & & & & & & \\
\hline KA & & & & & & & \\
\hline LU & & & $\mathrm{X}$ & & & & \\
\hline RE1 & & & & & & & \\
\hline RE2 & & & & & & & \\
\hline
\end{tabular}

Fonte: produzido pelos autores.

A variação também pode ser observada em relação aos sujeitos, dado que alguns deles, como, por exemplo, ER, ED e KA, utilizaram com muita frequência esse recurso, enquanto outros, como RE1, RE2 e FE, o usaram na intensificação de apenas alguns sinais. 
Já em relação ao alongamento do movimento, como se pode ver no quadro 4, a seguir, ele teve uma maior frequência na realização dos sinais CHUVA e SOFRER, sendo, portanto, menos frequente na forma intensificada dos demais sinais.

Quadro 4 - Alongamento do movimento como recurso para expressar intensidade (' $x$ ' indica que o dado foi excluído).

\begin{tabular}{|c|c|c|c|c|c|c|c|}
\hline \multicolumn{7}{|c|}{ Alongamento do Movimento } \\
\hline $\begin{array}{c}\text { Sujei- } \\
\text { tos } \backslash \text { Sinais }\end{array}$ & $\begin{array}{c}\text { ALÍ- } \\
\text { VIO }\end{array}$ & $\begin{array}{c}\text { CHU- } \\
\text { VA }\end{array}$ & $\begin{array}{c}\text { EXPERIÊN- } \\
\text { CIA }\end{array}$ & $\begin{array}{c}\text { FÁ- } \\
\text { CIL }\end{array}$ & $\begin{array}{c}\text { NÃO- } \\
\text { SABER }\end{array}$ & $\begin{array}{c}\text { SO- } \\
\text { FRER }\end{array}$ & $\begin{array}{c}\text { VON- } \\
\text { TADE }\end{array}$ \\
\hline CR1 & & & & $\mathrm{X}$ & & & \\
\hline CR2 & & & & $\mathrm{X}$ & & & \\
\hline DA & & & & $\mathrm{X}$ & & & \\
\hline ED & & & & & & & \\
\hline ER & & & & & & & \\
\hline FE & & & & & & & \\
\hline FL & & & & & & \\
\hline KA & & & & & & & \\
\hline LU & & & $\mathrm{X}$ & & & & \\
\hline RE1 & & & & & & \\
\hline RE2 & & & & & & & \\
\hline
\end{tabular}

Fonte: produzido pelos autores.

É digno de nota que a realização desse recurso em ALÍVIO (Figura 11), diferentemente dos outros sinais, ocorreu em alguns casos na sua fase de preparação. Isso deve ter resultado do fato de este sinal ser realizado com contato permanente e seu movimento consistir na mudança de configuração de mão, e logo, não envolver deslocamento espacial. Em nossos dados, também identificamos casos de alongamento do movimento desse sinal através de uma desaceleração do movimento de flexão do dedo indicador.

Figura 11 - Sinal de alívio na forma basal (1-2) e intensificada (3-4): preparação (1 e 3) e chegada no ponto da forma expressiva do sinal ( 2 e 4$)$.

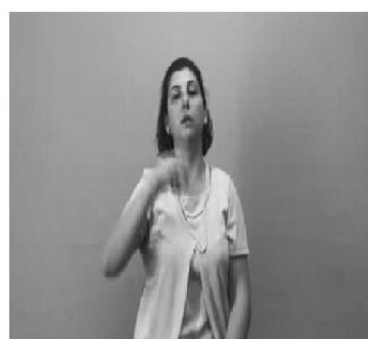

1

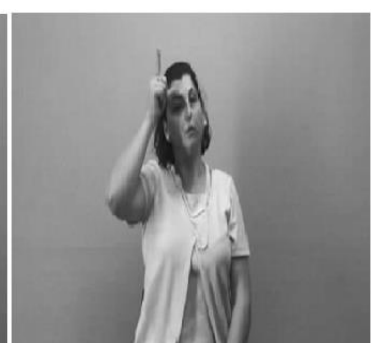

2

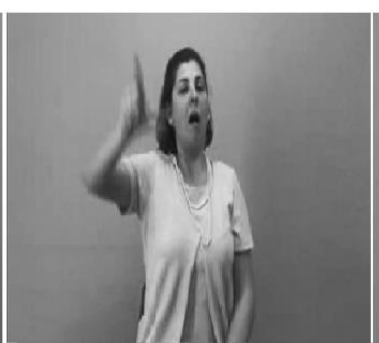

3

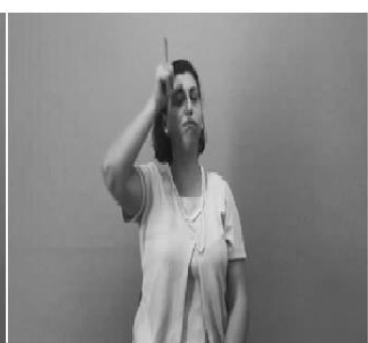

4

Fonte: produzida pelos autores.

Assim como nos dados de sobrancelhas franzidas, observou-se variação também em relação aos sujeitos no uso do alongamento do movimento. Embora CR1, CR2 e LU e RE1 o tenham utilizado com bastante frequência, FE, KA e RE2 o usaram na intensificação de apenas alguns sinais. 
Por fim, em relação à boca, foram observados diversos comportamentos desta durante a realização tanto da forma basal quanto da forma intensificada. De acordo com Sandler (2009), as atividades da boca se enquadram em quatro categorias. A primeira, designada por ela como componente bucal lexical, reúne casos em que os movimentos da boca fazem parte dos aspectos constitutivos do sinal (ver Figura 3b). Já a segunda, modificação adjetiva e adverbial, abrange configurações orais que modificam o significado original do sinal, por exemplo, agregando o sentido de prolongamento da ação. A terceira categoria, por sua vez, oralização, refere-se à articulação (geralmente não vocal) de palavras (oralização total) ou partes de palavras (oralização parcial) da língua falada. Por fim, a quarta categoria, designada por Sandler como gestos orais icônicos, se refere a certos movimentos da boca que co-ocorrem durante a produção dos sinais, utilizados, na visão da autora, para complementá-los ou para embelezá-los. Ela encontrou uma grande variabilidade de comportamentos da boca nesse caso tanto inter quanto intra-sujeito e, com base nisso, sustentou que não são linguísticos (lexicais/gramaticais), mas gestuais.

Em nosso trabalho, das 146 produções analisadas (formas basal e intensificada), encontramos 9,5\% de oralização total na forma basal e 8,2\% na forma intensificada. Com relação à oralização parcial, 12,3\% ocorreram na forma basal, e $6,1 \%$ na forma intensificada. É digno de nota que em muitos casos não nos pareceu claro se houve uma alteração no comportamento da boca da forma basal em relação à forma intensificada. Além disso, em tantos outros não nos pareceu claro a qual das atividades orais identificadas por Sandler na ISL eles correspondiam. Apesar disso, nossa análise, ainda que preliminar, revela que, assim como no referido estudo, deve haver na Libras uma grande variabilidade no uso de configurações e movimentos orais que co-ocorrem à produção de sinais. Isso é ilustrado nas imagens em 12, que se referem às diferentes realizações da forma intensificada do sinal SOFRER.

Figura 12 - Comportamentos realizados pela boca no momento da sinalização da forma intensificada do sinal SOFRER.

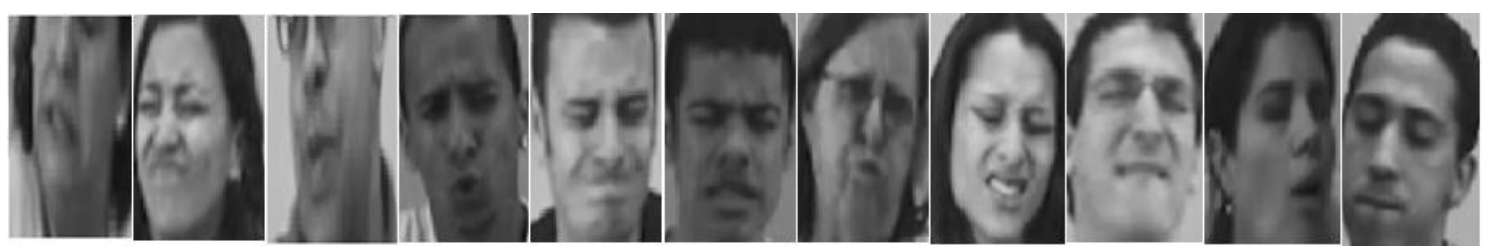

Fonte: produzida pelos autores.

As atividades da boca, de forma geral, e as alterações que sofrem na expressão de intensidade merecem um estudo específico, para que assim se possa entender seu papel nesse processo.

Para finalizar, vale dizer que embora, por um lado, os resultados aqui apresentados contrariem o trabalho de Xavier (2014), ao indicarem a não obrigatoriedade de mudanças em aspectos não-manuais ou em características dos movimentos na expressão de intensidade em Libras, por outro eles convergem com os achados do referido estudo. $\mathrm{O}$ ponto de convergência está no fato de que, assim como a duplicação de mãos, esses recursos parecem ser opcionais e variam tanto na frequência com que são empregados pelos sujeitos, quanto nos sinais aos quais são aplicados. 


\section{Considerações finais}

Este estudo objetivou avançar na descrição da expressão de intensidade em Libras, iniciada por Xavier $(2014,2017)$ e Santos e Xavier (2017), detalhando as mudanças nas expressões faciais e nas características do movimento que o referido autor sugere que sejam obrigatórias na expressão de intensidade em Libras, já que não observou o mesmo em relação à duplicação de mãos. Conforme os resultados obtidos, concluímos que a intensidade pode ser expressa por diversos aspectos não-manuais e manuais.

O uso das sobrancelhas franzidas e do alongamento do movimento foram os mais utilizados pelos sujeitos. Apesar disso, mesmo esses recursos não foram utilizados na realização da forma intensificada de todos os sinais analisados, o que sugere a sua não obrigatoriedade. Vale destacar que o aumento da duração na forma intensificada resultou estatisticamente significativo. Esse aumento, de acordo com nossos dados, resultou do alongamento do movimento, do alongamento da suspensão e do aumento do número de repetições. Observamos interação entre a estratégia de intensificação e a presença de contato apenas no sinal ALÍVIO. Provavelmente, por ser realizado com a mão em contato permanente com a testa (bem como por seu movimento consistir em mudança de configuração de mão, logo, não envolver deslocamento espacial desta), o alongamento do movimento se deu em alguns casos na sua fase de preparação e não na expressiva.

Por fim, este trabalho apontou a necessidade de um aprofundamento na descrição do comportamento da boca na produção de sinais, tanto na forma de citação, quanto na forma intensificada na Libras. Essa descrição, somada à reanálise das produções das três formas intensificadas de cada sinal por cada sujeito, deve colaborar com o debate sobre a natureza lexical/gramatical ou gestual do processo de intensificação na Libras e nas línguas sinalizadas.

\section{Referências}

BENZINGER, E. Intensifiers in current English. 1971. Tese (Doutorado) - University of Florida, Flórida, 1971.

FUKS, O. Intensifier actions in Israeli Sign Language. Gesture, v. 2, n. 15, p. 192-223, 2016.

KITA, S.; VAN GIJN, I.; VAN DER HULST, H. Movement phases in signs and cospeech gestures, and their transcription by human coders. Gesture and sign language in human-computer interaction, Springer Berlin Heidelberg, p. 23-35, 1998.

SANDLER, W. Symbiotic symbolization by hand and mouth in sign language. Semiotica, v. 174, n. 1/4, p. 241-275, 2009.

SANTOS, T. S.; XAVIER, A. N. Modificação dos parâmetros articulatórios na expressão de intensidade em Libras. Semana de Letras da UFPR, 19, 2018, Curitiba. Cadernos da Semana de Letras. Curitiba: Setor de Humanas, v. 1. p. 29-40, 2017.

WILBUR, R. B.; MALAIA, E.; SHAY, R. A. Degree modification and intensification in American sign language adjectives. Lecture Notes in Computer Science (Including Subseries Lecture Notes in Artificial Intelligence and Lecture Notes in 
Bioinformatics), v. 7218, p. 92-101, 2012.

XAVIER, A. N. Uma ou duas? Eis a questão! Um estudo do parâmetro número de mãos na produção de sinais da língua brasileira de sinais (Libras). 2014. Tese (Doutorado em Linguística) - Instituto de Estudos da Linguagem, Universidade Estadual de Campinas, Campinas, 2014.

XAVIER, A. N. A expressão de intensidade em libras. Intercâmbio, v. 36, p. 1-25, 2017.

XAVIER, A. N.; TKACHMAN, O.; GICK, B. Towards convergence of methods for speech and sign segmentation. ACOUSTIC WEEK IN CANADA, Hallifax, 2015. 